\title{
The Question of "Identities": Separate State Movements in Karnataka with Special Reference to Coorg
}

\author{
Vijay Poonacha Thambanda*
}

In Karnataka, separate state movements of North Karnataka (NK), Hyderabad Karnataka (HK), Tulu Naadu (Coastal Karnataka) and Coorg have attracted the attention of the media, scholars and politicians since the last two decades. The separate state movement in Coorg seems to be stronger and ideologically motivated when compared to the North Karnataka, Hyderabad Karnataka and Tulu Naadu movements. The Coorg movement has developed contacts with the other counterparts outside Coorg, either getting ideological support from CPI-ML organizations such as Karnataka Vimochana Ranga (KVR) or by getting membership in the "National Front for the Smaller States." Recently, Patil Puttappa, a veteran leader of North Karnataka and also the leader of Unification movement of Karnataka in the 1950s, supported the movement for the separate statehood for Coorg, and made allegations against the discrimination of the government of Karnataka. Interestingly, he immediately withdrew his statement soon after the pressure mounted on him. In fact, he had tried to communicate that the centralization of power in Bangalore, had sidelined the interests of the North Karnataka region like Coorg. It should be noted that the movement in Coorg, often used similar language and has attempted to explain how the "imperial Karnataka" exploited "other nationalisms" within Karnataka through its "power-brokers." Hence, the factor of "common enemy" for North Karnataka and Coorg could be seen only in this aspect i.e. Bangalore

* Department of History, Kannada University, Hampi, Vidyaranya, Hospet, Karnataka; vijay.thambanda@gmail.com 
cantered "imperial Karnataka."1 After this development, we hardly find any common "interest" of North Karnataka and Coorg in the political scenario. The questions of "Tulu Nationality" of Coastal Karnataka and "Kodava Nationality" of Coorg region (as well as "Kannada Nationality") are more or less being perceived on the lines of Joseph Stalin's "historically evolved stable community" by KVR (Saki 1998:4). However, Kannada and Kodava "National" movements have made attempts to imbibe CPI-ML's theoretical framework in the last decade of the twentieth century, despite their failure to launch a mass movement. The Tulu Separate State movement did not take off in spite of an attempt made by a former gagster during the early 1990s. ${ }^{2}$

Keywords: State movements, Coorg, Tulu state, Identity

\section{Separate State Movements in North Karnataka and Hyderabad Karnataka}

Patil Puttappa is a spokesperson for the Separate statehood for North Karnataka (NK) region as mentioned in the introduction. However, Vaijanath Patil, a former-Minister and MLA, agitated for the demand for the separate state for Hyderabad Karnataka (HK). Both belonged to the traditionally dominant Lingayat community which is very powerful in the public domain. It should be noted that Hyderabad Karnataka also comes under the geographical jurisdiction of the so called North Karnataka. Characteristically no body quarrelled for the identity of HK region in the politics of NK. These two "movements" went on agitating against "common enemy" rather than contradicting and disputing the geographical identities.

Most of the demands of the agitators of NK and HK are centered around the issues such as the establishment of High Court in NK, or the demand for the establishment of Southern Railway Centre in Hubli, or the implementation of Article 371 of the Indian Constitution in HK region, or the "negligence" of NK especially Hyderabad Karnataka region and so on. Interestingly, nowhere we can see these kind of separate state "movements" which are being articulated consistently. The geographical "identity" has been discussed very often in this case rather than the "identity" cantered 76 
on the "culture" as we identify in the case of Coorg. Vaijanatha Patil, the spokesperson of the HK separate state movement, repeated his demand for the separate state for Hyderabad Karnataka region on 1 November 2004. He said it was inevitable to possess a separate state since the subsequent state governments have neglected the problems of "North Karnataka region." He declared to observe the "Rajyothsava day" as a "black day." He criticized the failure of the government for not implementing the Article 371. He was unhappy with the people of NK region, who always opposed his move, when people of South Karnataka remained "silent" (Prajaavani 02.11.2004).

Meanwhile, the demand for the formation of new states for NK and HK regions has been widely condemned by left parties, intellectuals, $\mathrm{OBC}$ and Dalit organizations. Different political parties, intellectuals as well as Backward Caste organizations criticized the demand for the separate statehood for NK or HK regions. Democratic Youth Federation of India (DYFI) pointed out that this was the demand of some of the "disgruntled politicians" who had lost their credibility and political currency. They organized a mass rally on 31 October 2004 in protest against the demand for a separate state for NK and HK region (Prajaavani 02.11.2004). Some of the prominent "progressive" veteran scholars such as Shantharasa, along with his well wishers pointed out that dividing Karnataka was the agenda of the "communal politics" of BJP. They noted that BJP's idea of dividing state into smaller states would lead to the formation of a stronger Central government, which would be detrimental to the union government (Prajavaani 02.11.2004). In another statement, the leaders of Kuruba Samaaja (Shepherd community), one of the major Other Backward Communities of NK and Maadiga Samaaja (a Dalit community) have made it clear that the demand for a separate state for North Karnataka was against the interest of Dalits and OBCs. They pointed out that out of 96 MLAs, 71 MLAs hailed from upper castes, and 25 members belonged to Other Backward Communities and minorities. The press-statement the caste leaders also stated that 7 MPS out of 12 MPs belonged to upper castes and the remaining 5 members belonged to OBCs. They noted that ironically, 25 percent upper caste people of this region are representing 75 percent of the people, and consequently, Dalits and 
OBCs have remained most backward in this system. This part of Karnataka remained backward owing to the non-representation of Dalit-OBC communities (Prajavani 11.11.2004).

Most of the demands of the movements for NK are limited to short term goals. The leaders who agitated for the separate statehood in NK or HK argued for the short term plans instead of projecting the fundamental demands like eradication of organized corruption in NK region, where thousands of crores of rupees have been "invested" for the development of the region; atrocities of landed castes against lower castes particularly Dalits of the region; poverty; illiteracy; exploitation of labour communities, especially in the mining industry and agriculture; exploitation of women, especially Devadaasis, Jogammas, Basavis, organized prostitution; and so on. The urban middle class especially the lawyers of the district centres along with some politicians used to make a hue and cry for the statehood on liberal political lines. All of a sudden the demand for a separate statehood for NK has been stopped owing to the assurance given by the Ex-Chief Minister of Karnataka N. Dharam Singh who made it clear that a High Court Bench would be established in the NK region. Now, the agitators have started quarreling about choosing of the place for the establishment of the High Court Bench in their respective districts. It means that the "identity" question or the demand for the separate state is not at all a serious issue for the agitators or the politicians in NK or HK.

The demand for a separate state for Coorg is not a new phenomenon. This demand was being mooted even before the Unification of Karnataka. The demand for a separate state was renewed from time to time in the post-unification period. This demand received wider attention only when Karnataka Vimochana Ranga (KVR) extended its support to separate state movement of Coorg in early1990s. Separate State movement in Coorg also received support from Tamil National Movements in the mid1990s. Interestingly, the leaders of the separatist movement in Coorg succeeded in getting extensive support from BJP forces as well as retired military officers. We also witness the formation of an anti-separate state movement in this region, led by the organization of OBCs and Dalits of Coorg. The anti separatist movement has succeeded in getting the support of a few Kannada organizations 78 
primarily such as Kannada Shakthi Kendra, an organization that is fighting for the cause of Kannada with a rightist perspective. CPI (M) extended its support to the anti-separate state movement during this period. In this background, this paper discusses aspects such as the rise of separate state movements and the role of CPI-ML organization; the role of Tamil Nationalist Movements in Coorg; and the rise of anti-separate state movement in and outside Coorg.

\section{Kannada Nationalism: The Formation of Karnataka Vimochana Ranga and Kodagu Ekikarana Ranga (KVR)}

KVR was founded on 5, November 1989. KVR state the following circumstances for its formation: Firstly, the influence of revolutionary ideology is weak in Karnataka. Class struggle based on the politics of New Democratic Revolution is yet to cast its influence on the masses. It might take some more time before that is achieved. Thus the growing Kannada national movement will need more time and effort to be able to perceive and relate to the class demands of the peasantry and proletariat. Secondly, the particular manner in which the Kannada national movement has expressed itself insulates it from developing any perceptive antifeudal, anti-imperialist orientation. In other words class perceptions are numbered. What remains is an overpowering Kannada national consciousness. Thirdly, the Kannada national movement is at crossroads. The ideological and political weakness of the Kannada petty bourgeoisie makes it vulnerable to the influence of Kannada chauvinism and fascism. Unless the petty bourgeoisie which continues to lead the Kannada national movement, fight against its real enemies and asserts itself against Kannada chauvinism it will not be able to realize its aspirations. The betrayal by the Kannada comprador-feudal classes of 1956 must alert it against a second betrayal. Fourthly, there is the need to combat the rising Hindu communal Kannada fascist trend. The Kannada nationality cannot overcome its oppression by turning into an oppressor of national minorities within the state. Any attempt to do so will only further strengthen the hold of imperialism and feudalism on the oppressed Kannada nationality. The national, linguistic and ethnic minorities of Karnataka are the friends of the Kannada nation. The oppressed nationalities of India 
fighting for their right to self-determination including those that want to secede are the allies of the Kannada nation. The revolutionary movement which seeks to overthrow imperialism and feudalism and build in its place a new democratic India is a close friend of the Kannada nation.

The KVR seeks to preserve and strengthen the unity of the working class which has multinational character. The KVR believes that only by bringing the oppressed masses of all the nationalities of Karnataka to jointly fight against the common oppressors on the basis of a New Democratic program, is it possible to liberate Kannada nationality and all the national minorities of Karnataka from imperialist and feudal oppression. An independent Karnataka in a Federal India is one of its main slogans. It strives for salvation of the Kannada nation in a New Democratic India which will be constituted as a voluntary federation of nations (Jayaprakash, 1996). In this background, KVR supported the movement which is demanding for the statehood for Coorg.

The question of "identity" is an important aspect of the separatist movements in Coorg since 1950s and especially since 1990s unlike other separatist movements in Karnataka. ${ }^{3}$ The gravity of the agitation began with the formation of Kodagu Ekikarana Ranga in early 1990s. The KER was in the forefront of fighting the "corrupt Karnataka Government" in 1991. Mathanda Monnappa, the President of Akhila Kodava Samaja (a caste organization of Kodavas) brought all the splinter groups which were agitating in isolated pockets together under the common banner of the KER. According to a press report in the Economic Times, KER had already completed its mass awareness programme in the first phase of the agitation and was planning to launch the second phase. It had proposed to set up 65 shakas or branches (Economic Times, 17.03.1991). It demanded improvements in hospitals, roads, buses, revenue, tax, irrigation, forest administration, education and the taxation system of coffee. It should be noted that the problems of the rural poor, reservation or distribution of land never appeared in the demand-list of the KER. It pointed out that Coorg was depositing more than " 400 crores of Rupees" in the state's exchequer and in return Coorg was getting "step-motherly treatment" from Karnataka. In 1991, Mathanda Monnappa of KER 80 
gave an indication for the demand of a separate state. In a press note, KER pointed out that in case the government failed to give justice to the people of Coorg, KER would launch a movement to retain the "old order" of Coorg (Thambanda 2004). The voice of the demand for a "separate state" got the attention of the people. Under these circumstances, Karnataka Vimochana Ranga (KVR) entered the politics of the separate state movement of Coorg.

Karnataka Vimochana Ranga has its own ideological reasons to enter this politics. Like any other CPI (ML) party, KVR also opposed Communist Party of India (Marxist) and Communist Party of India for its support to the BJP's "centralized fascist central government" by "contributing in the name of national unity and integration!" (Prison-House 1993, 108). KVR believes that there is a need to bring the "oppressed masses of all the nationalities of Karnataka" for a joint fight against their "common oppressors." According to KVR, on the basis of a "New Democratic programme" it is possible to liberate "Kannada nationality" and all the minorities of Karnataka from "imperialist and feudal oppression." An "independent Karnataka" in a Federal India is one of its main slogans. It strives for the salvation of the "Kannada nation in a New Democratic India" which will be constituted as a voluntary federation of nations (Jayaprakash, 1996). This organization took keen interest in organizing the suppressed peasants of the Raichur region (1998) and attempted to mobilize them against native landlords and their collaborators. The most recent political expressions of this organization are evident in mobilizing students against the imposition of Hindi (1993), "Kudhuremukha environment movement" (1994-2003) and a rally organized along with the other left forces against communal forces in Bababudangiri in Chikkamagalur region (2003). KVR believes that the Karnataka government has been serving the interests of "feudalism and imperialism;" this "anti-people and reactionary government never had and will never have sympathy" for the Kannadigas. Hence, KVR advocates that the labourers, peasants, middle classes and democrats should come out from the clutches of the "state government of Karnataka," and possess a different identity. The "Kannadigas" of Karnataka and "Kodavas" of the Coorg region should lead the "revolutionary movement" against the state government, central government and their "imperial" 
masters to end the "oppression of the nationalities" in India (Janavimukthi, February 1998:18). It does so by taking recourse to Stalin's definition of nationality as "an historically evolved community" and it believes that in Karnataka along with Kannada, other ethnic communities like Tuluva and Kodava are also historically evolved stable communities (Saki 1998:4). Hence, KVR argued that the "democrats" should support the right to "self determination" of the people of Coorg.

Swathantra Karnataka (April 1991), the monthly periodical of KVR extolled Mathanda Monnappa, who declared the launch of a movement to demand a separate Coorg state in case the government of Karnataka failed to fulfill its hakkothayas (demand of rights). KVR argued that a group among the "capitalist-landed classes" of Coorg protested against the amalgamation of Coorg. It pointed out that Coorg was amalgamated as per the expectations of "capitalists" of Karnataka owing to the weakness of the "capitalist group" of Coorg. KVR said that the people of Coorg were disgusted with the 35 years of misrule of Karnataka and had no other alternative but demanding a separate state for Coorg. It declared that "Kodava Nationalism" has been supported by the people who speak the languages of "Kodava and Are-Gauda (Coorg Gauda)" that have deep rooted connection with the land. It praised the demands of KER as being genuine. Hence, KVR argued that the stance of all the "democrats" was to support the right to "self determination" of the "people" of Coorg. KVR gave some suggestions to KER to modify the strategies of the movement, ${ }^{4}$ those suggestions are listed below:

1) It will be a limitation of KER if it fights against the Karnataka government alone in relation to the underdevelopment of Coorg. The main role of the central government, which is suppressing all the "nationalities," should be noticed here despite fighting only against Karnataka only. The position of slavery of oppressed nationalism vis a vis central government continues and the basic problems are not solved even when the "warrior people" of Coorg gets a separate state or District Development Authority like Gorkha land. 
2) It will be of no use accusing the Mapilla timber merchants and immigrant Maleyalis, who are considered the enemies of Kodagu. They are struggling to make Coorg rich by their hard work. They are not the looters. Instead, the landlords and owners of the coffee estates should be punished for the exploitation of labourers and thousands of poor peasants, and also for shifting the capital to outside Coorg.

3) The movement should include poor among other castes than the people from Gaudas and Kodavas. Major demands like redistribution of land among the poor peasants should get a priority in the movement. Otherwise, KER would succeed in installing "Nanaiah" (a prominent politician of Coorg) in place of "Bangarappa" (who was the Chief Minister of Karnataka in 1991). Ultimately, this will help the land-owners and capitalists (Swathantra Karnataka, April 1991: 9-12).

Before the relationship between KER and KVR stabilized, one more organization with militant expressions entered into the politics of separate state on the day of Kaveri Tulasankramana, an auspicious day (18 October 1991) for the natives of Coorg. This organization was known as Liberation Warriors of Kodagu (LIWAK), and it became a favourite ally of KVR in the politics of Coorg.

\section{The Question of "Identity" and the Rise of Militancy}

A group of youth belonging to LIWAK took an oath to separate Coorg, the "sacred land of Kaveri" from the "gutter" of Karnataka. ${ }^{5}$ However, a law graduate N. U. Nachappa, the leader of LIWAK managed to establish a contact with KVR, which was in fact, looking for a man of "revolutionary" ideas and dynamism. Unlike the previous separatist leaders, Nachappa articulated powerfully as a demagogue and used the tools of the history of Coorg to mobilize the people in the name of "culture" and "identity." LIWAK pointed out that Coorg became an "orphan" after the amalgamation owing to the "illegitimate" relationship of "dirty politicians" like C.M.Poonacha, the then Chief Minister and K.Mallappa, the then Home Minister of Coorg State (1952-56), who "sold" Coorg to S. Nijalingappa, the then Chief Minister of Mysore (Karnataka) the "agent" of "imperial" Karnataka. Consequently, the "inhabitants" 
lost their "motherland" and were side-lined to the tragic chapters. ${ }^{6}$ Nachappa explained that Coorg had been converted into a "colony" to produce wealth for imperialist Karnataka. He declared "our protest is against the expansionist, monarchist, colonialist and invasive policies of Karnataka." $7 \mathrm{He}$ also pointed out that the "immigrants" "raped" the culture and environment of Coorg and built up their own "empire and colony" with the help of wrenched politicians. ${ }^{8}$ The ideological and political agenda of LIWAK has been expressed more clearly in the Memorandum submitted to the President of India, in 1992. It categorically divided the people of Coorg into two divisions, namely the "inhabitants" and the "immigrants." Some of the points made in the Memorandum are as follows:

1) The immigrants of other states (sic) have been poking their nose in the daily life of the inhabitants of Coorg by occupying the devarakadus (sacred forests), paisari and other kinds of government lands.

2) In the anticipated Coorg Legislative Assembly of the separate state, fifty per cent of the positions should be reserved for the inhabitants of Coorg in order to avoid the "foreign" elements and the people of other states including Karnataka.

3) At least one seat for a Coorg inhabitant should be reserved in the Lokasabha and Rajyasabha.

4) The government should declare that all the inhabitants called Kodavas, Gaudas, Jamma Kodagas, Yeravas, Betta Kurubas, Jenu Kurubas, Male Kudiyas, Koyavas, Heggades, Kodava Hajamas, Vokkaligas, Panikkas, Maleyas, Amma Kodavas, Kembatti Harijanas, Kapalas, Kodava Muslims and Airies as "Scheduled Tribes." So far as, the Kurubas, Yeravas, Kembatti Harijanas have been recognized as the STs by the government. Hence, the present STs should be called "special STs." Those who migrated to Coorg before 1947 like Brahmans, Coorg Lingayats, Banajigas, Vaisyas, Jahagilusabs, Vellalas and Devanga shetties are "permitted" to join the mainstream. 
5) The government should extend Article 371 of the Indian Constitution to protect the properties and culture of the inhabitants of Coorg. The government should declare Coorg as an "ethnic state."

6) Communal harmony has been disturbed by the immigrants of Kerala and other states. They have occupied the reserved lands of the government. Therefore, the government should evacuate them from Coorg and, prohibit the entrance of immigrants. Those immigrants who entered Coorg after 1, November 1956 should be expelled from Coorg immediately. The properties of those immigrants should be confiscated and distributed among the landless inhabitants and ex-service men.

7) All the inhabitants of Coorg belong to a martial race and they have an emotional relationship with the sword and the gun. Arms are an integral part of the rituals and religion of Coorg. The jamma holders of Coorg are already exempt from the Arms Act of 1962. LIWAK demands that the exemption be extended to all the inhabitants and constitutionalised.

8) The inhabitants have deep rooted religious relations with Talakaveri, Bhagamandala, Padi Iggutappa, and Irpu Rameshwara. Talakaveri is like the "Vatican church of Rome" for Coorgs. The government should hand over the administration of these temples to the local authorities since the government officials are neglecting the trustees of the temples.

9) Coorg is paying a tax sum of about 600 crores Rupees to the State exchequer. In return, the government is spending 32 crores. 22 out of 32 crores are spent for salaries and other expenses of the government official. The Red Indians of America lost their existence owing to the expeditions of Columbus. The Sindhi inhabitants lost their existence owing to India's Mohajirs. Now, it is the turn of the existence of the inhabitants of Coorg. The immigrants who came here after 1956 became the "brokers" between the government and people of Coorg. The inhabitants are infected by the "virus" 
spread because of the "illicit" relationship between the brokers and the bureaucracy. ${ }^{9}$

Finally, LIWAK stressed that its struggle was against colonialist, imperialist and expansionist Karnataka and not against India. It demanded a "Greater Kodagu" which included the regions of Amarasulya, Munjarabad and Periyapattana, which were part of Kodagu before 1834. In this context, they demanded the government to consider Coorg as the $26^{\text {th }}$ state of the Union of India. They warned that they would organize an aggressive movement in case the government fails to respond to their Memorandum within nine months. ${ }^{10}$ But, the government never bothered to respond the threat by LIWAK.

KVR extended its full support to the separate state movement stating that, "the people of Kodagu were disgusted after the amalgamation of Kodagu. The chela [sycophant] ruling class never attempted to develop Karnataka. It is natural that the people of Kodagu started feeling that they were marginalised under these circumstances." 11 However, LIWAK faced serious problems during these years particularly because of a series of investigations from the Home department of Andra Pradesh (and Karnataka at the later stages). There was a special investigation team of Andra Pradesh plugging the clandestine flow of arms from Coorg to "outlawed" People's War Group of Naxalites.

In 1998, an official publication of Karnataka Vimochana Ranga (KVR) has accepted the fact that LIWAK mooted the idea of "armed struggle" against the state of Karnataka (Janavimukthi, January 1998). In fact, in December 1993, the former Opposition Party leader in the Karnataka Legislative Council A.K.Subbaiah urged the government to suppress LIWAK's armed training camps at Maldare forest area of Virajpet taluk. He alleged that LIWAK had carried out this armed training camp with the assistance of "outside power circles." He cautioned that it would be impossible to rein in youngsters if they go out of control. He anticipated Punjab-model of terrorism would unfold in Coorg if the government fails to suppress LIWAK (Shakthi, 13.12.1993).

There were many complaints against the "goondaism" of LIWAK activists during this period. Within a short span of time, Nachappa 86 
faced an allegation that he had instigated the murder of his opponent Shanmugham. The police started interrogating Nachappa in 1994. Reacting to the vigorous investigations of Deputy Inspector General of Police Jeeja Harisingh, Nachappa abused her as a "license holding criminal" (Kodagu Mitra, 19.06.1994). Anyway, the government of Karnataka thwarted LIWAK's idea of "armed struggle" in 1994. As observed by Karnataka Vimochana Ranga, LIWAK became "silent" owing to an anticipated revenge from the government. As a result, Nachappa changed his strategy and formed a new organization called Kodagu Rajya Mukthi Morcha (KRMM), which adopted the "legal ways" of the long struggle like "pressure...compromise...pressure" tactics (Janavimukthi, February 1998).

\section{Manifestation of Kodava Fundamentalism and the Rise of KRMM}

LIWAK's spokesperson declared on 3, January 1995 that LIWAK has changed its name as KRMM (Brahmagiri, 09.01.1995). Nachappa particularly emphasized organizing Kodavas, the dominant caste of Coorg, through their caste organizations such as Kodava Samaja and Akhila Kodava Samaja. The Kodava Samaja groups are very powerful not only in Coorg, but also in various cities of Karnataka and India as well as abroad. There are hundreds of bureaucrats from IAS/IPS cadres, top military officials belonging to Commissioned ranks, business persons and a section of the elite who have associated themselves with Kodava Samaja all over India and outside. Field Marshal K. M. Cariappa, General K. S. Thimmaiah, Former Home Secretary of India, Muthanna, Former Attorney General of India, C.G.Somaiah, Former Railway Minister and Governor of Madhya Pradhesh and Orissa, C.M.Poonacha and hundreds of highly influential persons hailed from this caste. All of them were and still are associated with the Kodava Samaja (a list of the elites of this caste has been recorded by a retired military officer in a book [Ponnappa 1999, 230-284]). Kodava Samaja had organized more than 13 international Kodava conventions from 1988 to 2000 in the United States of America. These Kodava Samaja groups also run wedding halls, education institutions and other enterprises in various cities of India as well as in the remote villages of Coorg. It has its own 
website since 1997. Most of the Kodava Samaja groups have supported KRMM in spite of its initial reluctance during the end of 20th century.

Akhila Kodava Samaja (AKS) is basically a "cultural" organization of the Kodavas who live outside Coorg. It has its own "emblem, flag and caste song." The adharsha vakya or the "ideal sentence" of AKS is "Let's be wrong together than be right separately." 12 AKS gained much of its publicity only after the formation of Kodagu Ekikarana Ranga (KER). After the failure of KER in organizing the masses, Mathanda Monnappa, the President of AKS and also leader of KER extended complete support to KRMM, which had already determined to protect the "ancient culture of Ramarajya which existed before 1956." KRMM was also quick enough to project the President of AKS as a "spokesperson" of all the "Kodavas of the world" and also as the chief "thakka" (traditional leader of the Kodava caste) of Coorg society. In a way, AKS was portrayed and projected as a religious wing of KRMM, which gained much of its inspiration from the VHP of RSS. On the other hand, KRMM made use of the RSS/VHP/BJP activists very effectively. Subsequently, Nachappa popularized the rightist symbols such as "route march" with weapons and traditional dress such as kupya-chele, peechekathi (which, in fact, are used by the natives in some of the rituals). The BJP chauvinists strengthened the hands of KRMM in suppressing the "immigrants" especially the "Maleyali-speaking Keralites" more specifically the "Maleyalispeaking Moplas" whose population is considerable in rural Coorg. In November1997, the BJP MLA Ranjan Appachu, a Kodava by caste stated, "What is wrong in supporting the separate movement in Coorg? Our party will protest inside and outside the Assembly in case government prohibits KRMM" (Shakthi, 28.11.1997). In a letter to A.B.Vajapeyi, Nachappa wrote,

I find no equal (sic) terminology to express my happiness in order to congratulate you on your assuming the office of the Prime Minister of our nation. I may very well understand the rigours you underwent, the anxieties and ecstasies you fostered and the failures you have experienced during the past forty years. It is only your fortitude, patience and steadfastness that have taken you to [the] enviable position 
what [in which] you are today. I and my people pray for your success and many more years of [your] service (Kodagu Desha, April 1998)

He even heartily welcomed the Phokran "nuclear arms test" of the BJP government in May 1998 (Kodagu Desha, June 1998). The famous slogan "Akhanda Bharathadalli sundara Kodagu" or "beautiful Coorg in the undivided Indian continent" has attracted not only the RSS/BJP activists, but also many retired military personnel to KRMM. KRMM has succeeded to some extent in attracting a section of ex-service men. In 1992 itself LIWAK had urged the government to confiscate the properties of "immigrants" and distribute them among the ex-service men. For the first time in 1996, KRMM began to use the names of Field Marshal K. M. Cariappa and General Thimmaiah as symbols of the movement.

Surprisingly, KRMM was successful in gaining the support of high ranking retired military officers such as Lt. General B. C. Nanda, Lt. General Kariappa, Major General C. K. Karumbaiah, Col. M. A. Cariappa and others rather than the involvement of common exservice men. The retired military officers not only supported KRMM, but also actively participated in the agitations. Some of them even contributed articles to "Kodagu Desha," the mouthpiece of KRMM.

\section{Language-Identity: The Politics of Kodava Bhasha Sahitya Academy}

The formation of Kodava Bhasha Sahithya Academy coincided with the agenda of KRMM. Before going into the details of the politics of language-identity in Coorg, I would like to give a brief historical background of the formation of academies in Karnataka. Unification of Karnataka was completed in 1956 by bringing together Kannada-speaking geographical areas such as Hyderabad Karnataka, Mumbai Karnataka, Princely Mysore State, Regions which were under the supervision of Madras Presidency and Coorg State. In spite of completion of the unification of Karnataka, one could easily find three major language based regions with in the state of Karnataka, such as Kannada speaking communities, Tulu-speaking communities of Coastal Karnataka and Kodagu language speaking communities of the Coorg region. The 
representation of Tulu and Kodagu speaking communities have been recognized by the Congress government under the leadership of the former Chief Minister of Karnataka Veerappa Moily, a politician who hails from the Tulu region, through the formation of Tulu and Kodava Sahithya Academies along with Konkani Sahithya Academy in the early 1990s. It should be noted that Konkani language is also predominantly seen in Coastal Karnataka. It is interesting to note that the Karnataka government has already created thirteen more academies which include academies for Kannada literature, Folklore and Yakshagana (an art form popular in Coastal Karnataka), Kannada Development Authority, Fine-arts and so on. Kodava, Tulu and Konkani are the recent inclusions to the list of the academies that already existed. ${ }^{13}$

The aspirations of the Karnataka government did not materialize in the case of the Kodava Sahithya Academy as they did in the case of other regional academies. All the sections of the Tulu and Konkani speaking communities were incorporated in the respective academies while nominating members for the governing bodies. In fact, Tulu and Kodagu languages are the languages of the land and certainly do not belong to a particular caste or religion. Surprisingly, in the case of the Kodava Sahithya Academy, the interests of both the caste political leaders of the ruling party as well as KRMM went side by side. KRMM gained great success in hijacking the "Kodava Bhasha Sahithya Academy," an Academy being sponsored by the government of Karnataka to promote Kodagu literature. M. C. Nanaiah, who was the Law-Minister of the Janata Dal government and the Minister-in-charge for Coorg district took special interest in nominating members to the Academy. Theoretically, the Minister never supported KRMM, but in practice helped by recruiting their cadres in the Academy. U.M. Poovaiah, for example, an active supporter of the separatist organizations such as Moolanivasigala Sangha (An association of Original inhabitants) in the 1980s, Navanirmana Samiti in 1991-92 and an active supporter of KRMM, was nominated by the government for the post of President of the Academy for two terms. The Kodava Samaja Presidents of Bangalore, Mysore and Madikeri along with the President of "Akhila Kodava Samaja" are "permanent members" in the Academy. The Minister who hails from the Kodava caste has nominated all the members to the 90 
Academy from his own caste by marginalizing the people of the remaining 16 castes, who also speak "Kodagu" language as their mother tongue. In other words, there was not a single non-Kodava caste member in the Academy.

The Kodava Sahithya Academy, instead of promoting "literature and language," started organizing massive Kodava Samskrithika Melas- cultural festivals of "Kodavas" all over Coorg as also in Bangalore between 1995 and 2003. Literally, "Kodava" means both the name of a caste as well as the name of a language in the context of the twentieth and twenty first centuries. In fact, the predominant native language of Coorg was called "Kodagu" language till the beginning of the 20th century. Owing to social and political transformations after the emergence of coffee plantation and colonial rule, a section of this community started calling themselves "Kodavas" because the word "Kodagaru" includes all the sections of the people living in Coorg. The upward mobility of this caste also made its elites possess stronger identities in a changed political order. Hence, they wanted to get out of this identity (Kodagaru) by calling themselves "Kodavas" during the early days of British rule. Consequently, clans such as Sanna, Malla and Boddu Kodagas which had no marital or any other social relations among them came together as a homogeneous community called "Kodavas" during the colonial regime (Rob Cole 1947 (1871): 1-2; Richter 1887: 14-16; Srinivas 1989 (1952): 34-36; Thambanda 2000: 36-41). We can see a process of homogenization of castes in the case of Vokkaligas and Lingayats outside Coorg during this period. The dominant historiography of Coorg also equated the two meanings of the term 'Kodava," though they denoted caste on the one hand, and language on the other. Obviously, the powerful sections of Kodavas took advantage of this to state that Kodava language is the language of the Kodavas. They have continuously maintained a silence regarding the Kodava language speaking "non-Kodava" castes, particularly when sharing of privileges and constitutional powers was at issue. Therefore, "Kodava Cultural Mela" indicated that it was a get-together function of a particular caste, not the mela that promotes the spirit of the Kodava language. In this context, thousands of Kodavas (by caste) participated in the melas with traditional dress (and some of them with traditional swords and guns). Hundreds of youngsters participated in the aat-paat (sports 
and music-dance) and ummathat-bolakat (native dances) programmes. At the beginning, KRMM used to circulate its pamphlets in those melas. In the later stages, the activists participated in the official processions of the "Kodava" Academy by carrying the banner of KRMM. The family and caste gettogether at the melas became a significant factor in mobilizing people for the rallies of KRRM. People like Mathanda Monnappa, as a member of the Kodava Academy, as a "religious leader of the Kodavas of the world," as a hard core member of KRMM and, also as a respectable ally of the government of Karnataka played a key role along with the other "Kodava Samaja President members" of the Academy to mobilise people of the Kodava caste for the mass rallies of KRMM.

There is no doubt that the "cultural melas" of Kodava Sahithya Academy have helped KRMM organize hundreds of meetings in different villages, particularly in 1995 and also huge rallies in 1996 and 1997. In these rallies KRMM emphasized the need for the nyaya panchayath system of Kodagu (or the conventional judicial system of Coorg) with the leadership of the thakkas or traditional leaders (obviously under the supervision of the thakka of Akhila Kodava Samaja). It should be noted that the President of Akhila Kodava Samaja was portrayed as the chief thakka. As noted earlier he was being symbolized by KRMM as the religious leader of the Kodavas of the World. As a result of the politics of "cultural melas of Kodava Academy," Kodagu-Gaudas formed a "Gauda Academy" to promote and protect "Gauda Culture" and organized "Gauda Samskrithika Melas" in Coorg without the financial assistance from the government.

\section{Politics of Mass Rallies: The Rise of KRMM}

A section of bureaucrats from Coorg including some of the top police officials associated themselves with the politics of KRMM. There was a rumour in 1997 that the government was planning to punish the officers supporting KRMM. Reacting to that, Nachappa pointed out, "KRMM will protect those officers, in case the government takes action against them...Instead, the government must restrain the officers who are enjoying lavish life at 'race course' in Bangalore" (Shakthi, 30.11.1997). Interestingly, Lankesh 92 
Pathrike, one of the outstanding weeklies of Karnataka wrote that the agenda of KRMM fascinated many because there was no particular programme in the "manifesto" against the "insiders" of KRMM such as timber looters, land grabbers, anti-social elements, corrupt politicians and the local exploiters (Lankesh Patrike, 24.12.1997). All these factors contributed to KRMM's mobilization of hundreds of meetings in different villages particularly in 1995 and also huge rallies in 1996 and 1997. The Kodava melas of the Academy had been organized at Virajpet in February 1996 and at Napoklu and Ponnampet in February 1997. Similarly, KRMM organized rallies at Madikeri in November 1996, at Gonikoppal (Ponnampet) in February 1997, at Napoklu in April 1997, at Somwarpet in May 1997, and at Madikeri in November 1997. The "rehearsals" in the Kodava mela paid good dividends to KRMM. The two rallies at Madikeri and another rally at Gonikoppal were tremendously successful. More than ten thousand people participated in these rallies, and a section of the population enjoyed the rally with the traditional dress of Coorg (KRMM boasted that 70,000 people gathered in the convention held at Madikeri on 21, November 1997) (Kodagu Desha, February 1998).

The "Historical Madikeri Resolution-1996" passed at the Madikeri rally of 1996 demanded statehood for Kodagu and every participant offered himself to "die for the cause." This convention declared to choose the "Gandhian method" to achieve the desired goal. The Madikeri resolution has been treated as the political agenda of KRMM. Some of the earlier agenda of LIWAK have been included here with significant modifications. Some of the new inclusions are given below:

1) The immigrants from Kerala are incessantly exploiting and looting evergreen forests of the Western Ghats. According to an official estimation timber worth about 2.5 lakh crore Rupees have been looted between 1960 and 1996. The timber thieves of Kerala as well as the corrupt politicians are having their axes honed and fully equipped to fell the trees in future also.

2) KRMM advocated the "nyaya panchayath system of Kodagu" or the traditional judicial system of Coorg with the thakkas. 
3) Under the garb of socialism the sacred land is being disposed off to illegal immigrants. Under the name of tourism the places known for holy shrines are becoming abodes of debauchery. It pointed out that uniform reservation policy brought into effect in Karnataka is a political tragedy. All the people's representation from village panchayat to education institutions have gone to the illegal immigrants settled in Coorg. Even the office of the President of Coorg Zilla Panchayat has gone to the share of a rich woman, a migrant from Kerala. With the responsibility of safeguarding the interests of the original inhabitants of Coorg passing to her it has become an ideal case of a "Woolf looking after a flock of sheep."

4) The rulers are plotting to break the will of the volunteers of KRMM and are committing colossal violation of human rights. Karnataka government refused permission to the use of microphones in the foot marches of KRMM in the month of November and December 1995. "Thus it has curtailed the freedom of individual and the freedom of speech. We have no other recourse than to complain to National Human Rights Commission (NHRC) and United Nations Human Rights Commission (UNHRC)."

5) All the 23 separate state movements (including Coorg) have been accepted by major political parties such as BJP, Janatadal, Communist and Congress parties. They have also passed resolutions in favour of these movements. "We have dedicated our life to struggle years together to emancipate the lost Home land of ours. It may take 100 days, 100 months or even 100 years. We are ready to fight and are committed in our resolve."14 (emphasis added)

KRMM also criticized the government of Karnataka for its failure to carry out development works. It severely criticized that the multinational companies, Chettiers of Madras, Underworld Dons, NRIs settled in Dubai, Marwadis of North India and politicians with their black money are involved in grabbing land and business 94 
in Coorg. More strikingly, KRMM never advocated the "ST reservation" for all the inhabitants, which was enlisted in the early resolutions of LIWAK. Instead, it poured venom on the reservation system as explained in the above resolutions. Meanwhile, Nachappa presented a "charter of demands" to the President and Prime Minister of India on 3, July 1997. He also appealed to Kofi Annan, the Secretary General of UNO to interfere in the crisis and help them to obtain separate state-hood for Coorg (Thambanda 1998). In December 2000, he pointed out that a ship from Shipping Corporation of India would be charted sailing all the way to Geneva, the head quarters of United Nations. He noted that it enabled to ferry five to ten thousand people from Kodagu (Kodagu Front, 21.12.2001). But, this effort did not work out. Interstingly, KRMM proposed a budget for the "Kodagu Government in Waiting" during these years. The leader of KRMM made it clear that

Once it is in the saddle after the cherished goal of the $\mathrm{KRMM}$, a separate statehood for Kodagu, is attained, its government-in-waiting assure the nation that it would pledge itself in the name of the sacred and bounteous Cauvery Matha, to usher in a system of governance which should be the envy of all the bigger states of the Indian Union. ${ }^{15}$

\section{Politics of Alliance: The Influence and the Intervention of Tamil National Movements}

Unlike the previous separatist leaders, Nachappa articulated powerfully as a demagogue and used the tools of the history of Coorg to mobilize the people in the name of "culture" and "identity." He was thrilled by the attempts of Prabhakaran, chief of the LTTE particularly, in constructing a history and mobilizing the people. The LTTE traces the history of Tamils in Srilanka back to years before the Christian era (Oberst 1996: 141). In fact, LIWAK has managed to 'trace' the history of Coorg back to 4,000 years. ${ }^{16}$ It is interesting to find out the line of interpretation of history of KVR has similarities with the interpretations of LTTE. Karnataka Vimochana Ranga has struggled to give an "ideological" shape to the "oppressed nationalism" of Coorg in January 1998. KVR stated 
that the "class society" had emanated in the "iron age of Coorg history (1000 B. C.)." According to KVR "Coorg society" had formed its "nationalism" during the "transformation from the period of primitive communism to the period of feudalism" and, Karanataka's centuries old relationship with Coorg was manipulated by the Karnataka's "broker capitalist class" with the assistance of "broker Kodavas." It pointed out that one should accept the right of "self determination" if, the "Tulu" and "Kodava" "nationalisms" desired for separate states. It claimed to see the "oppression of Kodava nationalism" during the 41 years of administration by the "Kannada ruling class." It accused the government that the Kodava language, the symbol of "Kodava nationalism" had been denied as the medium of instruction and also the status of a recognized independent language had been denied to it (Janavimukthi, January 1997).

While referring to the LTTE movement, Peter Schalk points out,

The characteristics of this identity [Tamil], are not only language, Tamil and territory, Tamilam. In case of Ilavar [political identity], a part of their identity, namely their martial identity, is consciously singled out by glorifying insiders and demonising outsiders and made to represent the Tamilar as a whole in communication. This process of singling out 'tigerness' as a permanent characteristic of a people is of course a defensive and aggressive reaction to the lion's roar. It is not traditional. This tiger-identity is a reaction to Lankan majority rule and it had a gradual growin .... (Schalk 1997:38).

Interestingly, LIWAK, too, imitated the style of glorification of the "martial class" and, placed the face of tiger in its official emblem in the absence of a "lion's roar."

LIWAK made all kinds of attempts to mobilize people in "traditional" ways. The horatagararu (agitators) including women used to hold the guns and odikathis (traditional sword) on the dais of the public meetings of LIWAK (Shakthi, 10.05.1993). LIWAK recruited the youth and trained them for a month. It had three groups of agitators. The first group was called "core activists." The second group included the activists from villages, and the third 96 
group was the sympathizers and fans. The core members had separate identity cards (Kodagu Mitra, 19.06.1994). On another occasion, about 60 youngsters received training on the lines of LTTE for three days from ex-service men in 1993 in the forest-belt of Seethe Thopu Betta, near the Periyapattana border. For them, Prabhakaran, the Chief of the LTTE was the role model in their fight. Hence, they determined to protect the nature and environment of Coorg. Ironically, all the trainees ate a curry made from a kadave (an elk, the Indian Stag) during their training period in the forest (Veeranadu, 23.04.2001). As pointed out earlier, LIWAK changed its tactics and continued its agitation in the name of the new organization called KRMM owing to the pressures from the government.

KRMM got the membership of "National Front for Smaller States" in 1997 and consequently, was able to obtain "friendship" with leaders such as Sibu Soren of Jharkahand Mukthi Morcha (Kodagu Desha, February 1998). ${ }^{17}$ In another major development, KRMM began to develop close relationships with the "Tamil Nationalist" groups in1998. Vazhappady K.Ramamurthy, the Minister of Petroleum and Natural Gas in the coalition government of BJP as well as the leader of Thani Thamizhar Kazhagam (TTK) wrote a letter to the Prime Minister on 6, July 1998 stating,

I would recommend the demand of the Kodagus for the grant of a separate statehood or alternatively for the creation of a second state Re-organisation Commission paving way for putting forth their claim before the commission. I sincerely hope that my recommendation will receive from you personal intervention and serious consideration. 18

This news was reported in all the local newspapers on 19 July 1998. TTK General Secretary K. Nagaimugan, in a Press note dated 8 August 1998 congratulated Ramamurthy for his "bold letter" on statehood for Coorg. He said all the 39 MPs of Tamilnadu would support the demand for Coorg Statehood. Consequently, local newspapers of Coorg have started condemning the interventions of the politicians of Tamilnadu. According to a local newspaper of Coorg, the organization of Nagaimugan was the arch supporter of LTTE. Hence, Nachappa was prepared to victimize "the trusted 
ones" by making an alliance with "Rastadrohigalu," the antinational elements (Veeranadu, 23.04.2003). In August 1998, the Communist Party severely criticized the unwanted intervention of the person of a different state in the affairs of Coorg. Professor Chidananda Murthy of KannadaShakthi Kendra, while attacking TTK and KRMM, criticized the unnecessary interference of Tamilnadu. The district-in-charge Minister also criticized the role of Ramamurthy in the media. Reacting to the anger of the Karnataka government and people, Nagaimughan requested the Indian Home Minister demanding ' $Z$ ' plus security for Nachappa in anticipation of the violence from Kannada oraganisations (Andholana, 29.09.1998). The local government authorities deliberately acted too insensitively to the politics of identity. They are not even concerned about the complex relationship existing between different linguistic states in the Indian Union. Proper response was needed from the Karnataka government when a leader of the Tamil fanatic organization provoking people of Karnataka in Coorg, since cauvery water dispute was a very sensitive issue both for the people of Karnataka and Tamilnadu. Consequently, in November 2000, Nagaimugan opined:

The Karnataka State Assembly should pass a resolution for the re-creation of Coorg State from Karnataka. This would give a permanent solution to the Cauvery water dispute and also to the recurring clashes between Tamils and Kannadigas...the restoration of Coorg as an independent state, the dispute over sharing of cauvery river water can be solved permanently since Coorg is the birth place of the river (Coffeeland News, 18.11.00).

He urged the Chief Minister of Karnataka, "to invite the CNC leaders for a discussion over the issue and towards their recommendation to the Union Government and the Constitution Review Committee" (Coffeeland News, 18.11.00). The government of Karnataka did not take Nagaimughan and his associates seriously.

When the government of Karnataka initiated discussions with KRMM with the mediation of M.M. Nanaiah, the District Minister and a sympathizer of KRMM, the members of anti-separatist movement in Coorg (Kodagu Praja Vedike), Kannada Shakthi Kendra, and a large number of Kannada agitators protested against 98 
the move. They were also protesting against the rally of Nachappa alleging that he "brought huge sums of money from Tamil movements" and that the government should conduct an enquiry about it (Kannada Prabha, 09.11.1999) (For details see Thambanda 2004).

As a recent instant of his strategy and compulsion, Nachappa once again changed the name of KRMM as Coorg National Council (CNC) in 2000. This time he was very straightforward in negotiating the demands. He gave up the pseudo-ideal of "representing the entire inhabitant Communities" or talking about issues such as the problems of ex-service men, tribal welfare and so on. Priority had been shifted from the "underdevelopment" of Coorg to the demand for a "racial status" to the "Kodavas." At this stage, CNC was transformed into a pro-Kodava casteist and racist organization. Nachappa asserted, "We refuse linguistic minority status, because it will only guarantee us seats in educational institutions. Kodavas are a separate race... We are not a linguistic minority but a racial minority" (Kodagu Front, 30.11.2000). CNC declared, the Kodava community, by virtue of its microscopic numerical strength, should have been automatically protected by the Karnataka state, it has not happened till date and hence the demand for accordance of non-religious racial minority status for the race (Coffeeland News, 24.10.2000).

In the mean time, thousands of Kodavas participated in the "Delhi Chalo programme" of CNC held at Delhi on 21 November 2000. $\mathrm{CNC}$ and the office bearers of Delhi Kodava Samaja, along with the delegates of Karnataka Tamil Association (which played a crucial role in the release of Kannada cinema icon Dr. Rajkumar from the hands of the forest brigand Veerappan in 2000), presented a Memoranda to the offices of the Prime Minister, the Home Minister and Justice Venkatachalayya, the Chairman of the States Reorganisation Committee, demanding a "constitutional guarantee to protect the racial identity of Kodavas" through a separate state for Coorg. It should be noted that along with Karnataka Tamil Association, Jharkahnd Mukthi Morcha, Gorkha land, Bodoland, Vidharbha, Saurastra, Telangana, Poorvanchal and Pranchal Pradesh presented Memoranda to the offices of the Prime Minister and others on the same day (Coffeeland News, 22, November 2000). 
These organizations also urged the Commission to recommend to the government to bring amendments to the Constitution so that the "Kodavas" get an appropriate guarantee in retaining their "racial" heritage and right to hold arms without license. They also argued, "a Kodava by birth must hold this exception and this should become his personal law that means this exemption must be available to him in other States and Nations" (Kodagu Front, 19.01.01). Replying to various Memoranda, the Chairman of the Reorganisation Committee recommended to the government certain developmental programmes and did not subscribe to the separatist demand.

\section{Elements of Protest: Emergence of Anti-Separate State Movement}

Historically, all the Kodagu speaking communities have been associated under the hegemony of the Kodavas. For the first time in the social history of Coorg, the backward and Dalit castes rejected the "Kodava hegemony" and, opted for an alliance with their counterparts on equal terms. This part of the paper explains the historical situation, which compelled the formation of those alliances of the Kodagu speaking backward castes and dalits, Kannada speaking backward castes and dalits, and minorities in the name of Kodagu Praja Vedike (KPV). The relationship of the Communist Party of India (M) and the new alliance under KPV has been discussed in this section. This section also explains details of the nature of protest from the Vedike, as well as its confrontation with KRMM to take control of the politics of the separate state movement.

\section{Early Protest: Formation of Kodagu Moolanivasigala Sangha and Kodagu Kannadigara Sangha}

The seed of opposition was weak and mild by the Backward Castes and Dalits in 1995 and 1996. For the first time, in November 1995, the Kodagu Moolanivasigala Sangha (KMS) or "Inhabitants' organization of Coorg" of the Kodagu language speaking nonKodava Backward castes protested against the ideology and leadership of KRMM. A few retired officials from Heggade, Airi and Amma-Kodava castes organized anti-separatist organization called Moolanivasigala Sangha, under the leadership of K. M. Subbaiah. In a press statement, they pointed out that the backward 100 
communities of Coorg had suffered a lot during the administration of Coorg state, and that they were emancipated only after the amalgamation of Coorg with Karnataka. The people of the backward castes were denied employment and other privileges during this period. They protested against KRMM for its false propoganda of "representing all the inhabitants of Coorg." They condemned KRMM's silence when the government through its Kodava Minister nominated Kodavas and the "Presidents" of Kodava caste organizations alone for the "Kodava Academy." They questioned why the so-called organization of the "inhabitants" did not protest against the attitude of the government for not accommodating representatives from the remaining 16 moolanivasi (inhabitant) communities who also speak Kodagu language as their mother tongue. They condemned the betrayal by both the government authorities and the KRMM, and gave a call to the people to reject the hypocrisy of KRMM. They protested against the misuse of the tag of "inhabitants" for the selfish motives of the narrow minded leaders of KRMM, who, in a way were contributing to the hierarchy of the caste system in Coorg (Andholana, 08.11.1995).

Kodagu Kannadigara Sangha or the "Organisation of Kodagu Kannadigas" under the leadership of N. S. Deviprasad, a well known theatre personality extended full support to KMS and attacked KRMM towards the end of November 1995. He pointed out that the people of Coorg had given their verdict by defeating the "separatist party" which stood for the separation of Coorg in the 1950s. He condemned:

the people who supported the British government...who assisted them in the exploitation of the people ... who mourned when the British left India, thinking that a separate Coorg state was the gift handed over to them by the British in remembrance of good memories ... why the people kept silent even though they had suffered in the hands of the dominant groups when Coorg was a separate state. The elder people should explain how the younger generation had suffered, been humiliated and experienced the mental trauma during those days. People are silent owing to the fear of KRMM ... it does not mean that the people are behind KRMM. They should not understand the silence as an acceptance of 
KRMM . ... There is a rumour that KRMM is training the political terrorists in Coorg. It should be investigated thoroughly (Andholana, Prajavani, 22.11.1995).

The opposition of other sections of Coorg society slowly gathered pace during this period. An organization of the Kembatties, the Kodagu speaking Dalits, in a press statement severely condemned the Kodava Academy for inflicting humiliation and isolation on the Kembatties in the so called aat-paat (sports and music-dance) competitions of the "cultural melas," which organized separate aatpaat competitions/programmes for Kembatties, Kudiyas and other Kodagu speaking Dalits. The President of the Kembatti caste also pointed out that the government was planning to distribute traditional musical instruments (valaga sets) to them in the melas instead of accommodating them in the reservation under "Scheduled Tribe" category for which they had been fighting for decades. The Kembatti leader remarked that they wanted to become the respected and educated citizens like their neighbours instead of becoming "permanent drum beaters" (Andolana, 02.02.1996). Supporting the claim of the Kembatties, Kodagu Moolanivasigala Sangha (KMS) pointed out that if the Academy was interested in protecting "culture" they could supply the peeche kathi, odikathi, thodang (the popular assumption is that these ornaments are usually worn by the upper caste men during some rituals) to the Kembatties instead of supplying the "band-set" instruments. KMS ridiculed the government and its agencies like Kodava Academy for their attempts at making the Kembatties "permanent drum beaters" along with jeetha (slavery) (Andholana, 25.02.1996). As a result, the Academy dropped the separate aat-paat programmes for the Dalits, but, successfully distributed the socalled "traditional music instruments."

In the meantime, Kodagu Moolanivasigala Sangha filed a petition in the High Court of Karnataka through A. K. Subbayya, a noted advocate and the Former Opposition leader in the Legislative Council, against the government of Karnataka for "illegal nominations" for the "Kodava Academy" in the High Court of Karnataka. It should be noted that the non-Kodava organization, KMS, took the assistance of A.K. Subbayya, who belongs to the Kodava caste. The government was forced to nominate three 102 
members from non-Kodava Kodagu speaking people (not from Dalits) before the High court could pass a verdict. This is considered to be the first victory of Kodagu Moolanivasigala Sangha against the upper caste elements of the government and KRMM.

Alliances of Other Backward Castes and Dalits: The Emergence of Kodagu Praja Vedike

The anti-separatist, anti-upper caste and anti-upper class sentiments slowly crystallized in the shape of an organization during the first half of 1997. Most of the attacks of KMS or Kanndigara Sangha had been restricted to press statements and writing petitions to the government agencies. Most of the leading local vernacular as well as English language newspapers except a weekly called Kodagu Samachara never attempted to accommodate the anger and insecurity of the real "oppressed classes" of Coorg. Kodagu Samachara, however, took risks in publishing articles of anonymous writers (for example "sathya") against the demand for statehood since the beginning of 1997 despite its small circulation and threats from fundamentalists like Mathanda Monnappa, who is widely known as "Khomeini of Coorg" in anti-KRMM circles. Simultaneously, the Communist Party of India (Marxist) started posing serious objections to the propaganda and ideology of KRMM. It should be noted that both Kodagu Samachara and CPI (M) have their base at Virajpet, where KRMM had its real strength. The Communists are politically weak compared to other political parties like Congress and BJP in the district. Some of the articles gained wide attention particularly of organizations like KMS and Kannadigara Sangha. In the mean time, both these organizations joined together and formed a new organization called Kodagu Praja Vedike (KPV) or the "Forum of Kodagu People." This is an organization of land-holding backward communities (including Kodava-language speaking people), Dalits, minorities and labourers. The KPV elected N.S.Deviprasad and K.R.Vidyadhara, an advocate as the conveners. Ten thousand copies of the agenda of KPV were circulated throughout Coorg amidst protests from the KRMM volunteers in October 1997. KRMM made many attempts to suppress the organized opposition of Kodagu Praja Vedike (KPV). KRMM's effort at encouraging its own fake organization called 
"Kodagu Praja Parishath" against the KPV did not give any fruitful results. The title page of the agenda of Praja Vedike explains:

Kodagu Praja Vedike is a non-political organization of the exploited, backward, Dalit and working classes of Coorg. The primary objective of the Vedike is to agitate for the constitutional rights of the exploited and the oppressed. This organization is not formed against any class or caste since it is determined to struggle for the rights of the exploited and working classes of all the communities. The community interests of Kodagu have made Kodagu Praja Vedike protest ideologically against the demands for a separate state. Vedike objects to the followers of the British, who glorify British regime as Rama Rajya as well as their ideology and also objects those who dedicate themselves to re-establishing Rama Rajya. This booklet explains the exploitative nature of Kodagu Rajya. ${ }^{19}$

The KPV booklet asserted that in no way KRMM could represent the inhabitants since the decisions of the backward communities and Dalits among the "inhabitants" do not support the separatist cause. They argued that in the so-called Rama Rajya slavery had existed under the supervision of local collaborators, the members of the dominant community during the British regime. It pointed out that who were evidently beneficiaries in the "Rama Rajya" before 1956, and who would benefit if at all "Rama Rajya" revived. KPV also explained how these local collaborators assisted the British in extracting hitti bitti chakri or forced labour from their own people and from poor peasants. It ridiculed the attitude of the Kodava Academy and its caste politics in collaboration with KRMM and the representatives of the government (Thambanda, 1998).

KPV explained the origin of coffee plantations in these parts in the 1850s. According to it the rich peasantry were the first to invest and establish estates. As these estates and plantations demanded a larger labour force, these estate owners themselves had brought in labourers from the neighbouring states. It was obvious that poor Maleyalis migrated to Kodagu for their livelihood to work in these coffee estates since Kerala is the border of Coorg. It is also true that a majority of the coffee estate owners depended on the cheap labour brought in from Maleyali and Tamil speaking regions. 104 
Consequently, Coorg is considered to be one of the best coffee producing regions in India since the days of colonial administration. And, over the period, some among the labouring communities have established themselves economically and politically through education in independent India. KPV wondered why the so-called inhabitants should feel jealous if somebody becomes the President of the Zilla Panchayat or attempts to live like their neighbours (Thambanda, 1998). It argued:

How could anybody call them immigrants? If the Maleyalis were to be treated as immigrants, then there should be an amendment to the Constitution calling them "domestic immigrants" within the country... The state capital will be at Madikeri if Kodagu becomes separate. Madikeri will have a High court too. The offices of the Chief Minister, Inspector General of Police, Chief Secretaries of the entire department will be established at Madikeri at the cost of poor peasants. People would need to visit Delhi in case they are not satisfied with the justice given in such a Kodagu state. It is unimaginable for the poor, backward and working class people to travel from Madikeri to Delhi as they are not even in a position to visit Madikeri town from their villages. Hence, the separate state for Kodagu would be a hell to the poor people... KRMM is misleading the people through false information that Coorg is paying Rs.600 crores as tax. In fact, Rs.600 crores is the "income" of the district. How could it be possible when the District Minister declared that the income of Kodagu does not exceed Rs.72 crores? KRMM is misleading the people by equating the terms called "income" and "tax" synonymously... As a Kodava he Cheppudira Poonacha and others dedicated themselves to leading the Indian national movement in Coorg. Now, KRMM is abusing him that he sold Coorg to the politicians of Karnataka. This is the gift of KRMM for freedom fighters on the occasion of the golden jubilee of Indian Independence... Most of the Gods of Coorg are traditionally connected with Kerala. The spirits of the ancestors (karana) utter the name of "Bythoorappa" during the rituals of natives, including Kodavas. Most of the sacred places of these gods are 
situated in Kerala. Can KRMM oust these Gods which have a Kerala origin along with the immigrants of Kerala? If yes, what would be the fate of okkas (the joint families), which have been formed in the names of the ancestors, who have their origins in Kerala? Do no $t$ target them as "immigrants" like the Nazis did and do not divide the Indian people for narrow interests. Hence, the right of solving the questions of land -water-culture belongs to everyone who lives, grows, and dies here. The birthright of protecting Coorg has nothing to do with the fundamentalist organizations like KRMM, which do not have democratic principles and depend on a single person. ${ }^{20}$

Praja Vedike also noted that:

There are problems such as sharing of land and water resources besides unemployment, corruption, foreign investment, influences of multinational companies and exploitation of Indian capitalists, the influential timber lobby on which the KRMM is not prepared to have a debate (The Hindu, 21.05.1999).

The KRMM leaders including District BJP President K.G. Bopayya criticized KPV stating that "it divided the people on caste lines and also hurt the sentiments of the Kodavas." But, the Communists condemned BJP for its "unscientific allegation" against the booklet, and invited all of them for an open discussion on the "agenda" of Praja Vedike (Kodagu Samachara, 07.01.1998).

\section{Phase of Confrontation: Conflict between the Movements}

Separatist and anti-separatist movements organized a series of rallies and counter-rallies between 1997 and 1999. In fact, KRMM started organizing rallies since 1995. It was countered only after the formation of Kodagu Praja Vedike. The bundh call given by the KRMM thwarted by Praja Vedike on $3^{\text {rd }}$ December 1997. The Communist Party of India (Marxist) condemned the BJP for supporting the secessionist position of dividing people of democratic India as "inhabitants" and "immigrants" on the one hand, and, propagating "Hidutwa," "Hindu nationalism" and "imperial Hinduism" on the other. It criticized BJP's double106 
standards and the hypocrisy of projecting itself as the protector of "all the Hindus" while where Maleyali-speaking Hindus were tortured by a combination of KRMM -BJP elements in Coorg (Kodagu Samachara, 03.12.1997). The bundh was a complete failure in Somwarpet taluk and gained a partial success in Madikeri taluk. KRMM succeeded only in Virajpet taluk, where the population of the Kodavas is dominant (Andolana, Shakthi, 04.12.1997). The situation was very tense in 1997 . While explaining the situation of December 1997, Indian Express reported,

The recent violence at Virajpet, which left one person dead and property worth lakhs destroyed following the killing of two youth, has left non-Kodavas in the region, living in a shadow fear. The disturbance was apparently triggered by the ongoing agitation of the KRMM demanding a separate state for Kodagu...The movement has regions of South Kodagu as its major support base though the activities of KRMM have found resistance in areas which have the traditional Kodava [Coorg] Gauda population...The Virajpet violence, which saw many media persons also being targeted simply because they were not Kodavas but people from the neighbouring districts, who have settled there for decades and the attacks on properties of the minorities, have given KRMM a sectarian hue . . . its antiminority stand against settlers from other parts of the State apart from other long time settlers of the region, has evoked strong reactions from many people's organizations in Mysore .... The State has virtually no control over these forces. There have been instances in the past when KRMM youth have openly attacked policemen and even officers of the rank of DYSP and got away scot free. The situation is because many Kodavas in the administration are sympathetic to the cause and prefer to turn a blind eye .... The impunity with which these KRMM activists take on the police was on ample display at the Virajpet violence when they attacked policemen, including the Superintendent of Police, the gun man of Deputy Commissioner and torched many police vehicles (Indian Express, 23.12.1997). 
The signs of the decline of KRMM could be seen from the last week of November and December of 1997 when Nachappa had overestimated his strength by under estimating the view points of anti-KRMM organisations. In spite of all these developments he writes, "The false concerns, rhetoric, cry have been started all of a sudden! How could it be possible without any reaction since six and half years! The bundh was successful despite the protests!" (Kodagu Desha, February 1998). Karnataka Vimochana Ranga also endorsed that the bundh call of 3, Decermber was a "grand success!"(Janavimukthi, February 1998).

The confrontation between KRMM and Kodagu Praja Vedike continued till 2000. In the meantime, KRMM faced internal problems. Factors such as the financial mismanagement of Nachappa and the "Kodava racist politics" have been condemned by the former leaders of Kodagu Ekikarana Ranga and the President of Akhila Kodava Samaja. The leaders of these groups came out from KRMM and began criticizing its sectarian politics (For details, see Thambanda 2004). All these factors forced Nachappa to form a new organization called "Coorg National Council" (CNC). He gave up the pseudo-ideal of "representing all the inhabitant Communities" or talking about issues such as the problems of ex-service men, tribal welfare and so on. Priority had been shifted from the "underdevelopment" of Coorg to the demand for a "racial status" to the "Kodavas." At this stage, CNC was transformed into a pro-Kodava casteist and racist organization. Nachappa asserted, "we refuse linguistic minority status, because it will only guarantee us seats in educational institutions. Kodavas are a separate race .... We are not a linguistic minority but a racial minority" (Kodagu Front, 30.11.2000).

\section{Conclusion}

The CPI (ML) has been organizing the oppressed tribal's, landless labourers and poor peasants in various parts of India. Achin Vanaik points out that in China and Vietnam the repressive apparatuses were far weaker, and great political strength was derived by the leadership of the Communist parties from the fusions of the struggles for national and social liberation. He states: 
The very backwardness and autarkic character of oppressed classes of the countryside also helped determine the particular paths of these revolutions. But these conditions were largely absent in India. Capitalist transformation of agriculture was proceeding fast. Agriculture was much more integrated with industry and the urban economy (it is noteworthy that many of the strongest Naxalite bases were to be found among the tribal's whose economy and culture were less integrated into the mainstream); and there was powerful and highly centralised repressive apparatus (Vanaik, 1990:184-185).

These organizations have taken roots in specific regions of the countryside with local activists drawn from the most oppressed layers such as tribal's, landless labourers and poor peasants (Vanaik 1990:185, 187). In the given situation of post-colonial India, these groups very often overwhelmed with their ideals failed to evolve the strategies of countering the repressive centralized powers or to sense the multi dimensional power centres of Delhi government.

The CPI (ML) groups actively entered into the politics of separate state movement during 1990s. The CPI (ML) groups of Kanu Sanyal and Vinodh Mishra entered the Gorkhaland movement, and the CPI (ML) groups made an alliance with Jharkhand Mukthi Morcha (Nirmal group) during the separate state movements (Kumar 1998:99,121). For KVR, separate state movement of Coorg was a new experiment where it avoided its physical interference; instead, it boosted the so-called ethnic groups to uphold the "nationalist" spirit of the self-determination movement. Till 1998, KVR and CPI (ML)-PWG groups discovered Joseph Stalin's "historically evolved stable community" while explaining the "nationality" of Coorg (Saki, 1998:4). But, the transformation of "a historically evolved community" or "oppressed nationalism" of Coorg into a mere "Kodava Casteist/racist" organization is an indication of the failure of the out-dated jargons, which failed to yield any desired results. The mere imitations of the Tamil National movements or Jharkhand or Naga or Mizo movements did not help these organizations in launching a much-needed peoples' movement in Coorg. Consequently, these imitating nationalisms end disastrously 
without proper historical situation and experience. The distortions or glorifications of history for the benefit of the near future do not give positive results for the new social movements, which, in fact require more pragmatic answers to the problems of the "real oppressed" groups.

Leaders of Kodagu Praja Vedike belonging to Kannada-speaking Kodagu Gauda (Vokkaliga in general) and Lingayat communities have considerable influence with the caste groups of Vokkaligas and Lingayats of other parts of Karnataka, who, in a way are the strongest political force in Karnataka after its Unification. KPV felt that the demand for separate state and the claim for separate "identity" under the hegemony of the Kodavas are a major threat to the interests and existence of backward castes, dalits and minorities. It is appropriate to say that the lack of Dalit leadership could be seen in the organisation of Praja Vedike, even though Vedike made attempts to speak several issues on behalf of Dalits. Communist Party of India (M) always maintained a distance from Praja Vedike even though it does not have major differences regarding programmes against fundamentalist Akhila Kodava Samaja or even KRMM. It always extended "issue-based" support to Vedike rather than associating with the caste based alliance as it is more comfortable with "class" based alliance. Chidhananda Murthy, the staunch supporter of KPV has been portrayed as the rightist element associated with Hindutwa forces (Nair, 1996: 28092815). He had to change his position after his frequent visit to Coorg during these days. In his writings, he severely attacked the role of the "large number of BJP activists in the sectarian movement led by KRMM." He also wrote that CPI (M) was the only political party that had been protesting against the unjust demands of KRMM, particularly at Virajpet, where KRMM had a considerable force. He emphasized that the "working and depressed classes" of Coorg got freedom only after 1956, and not in 1947 (Prajavani, 19.02.1999).

On the other hand, Karnataka Vimochana Ranga played its role like any other liberal political party of India, of course with the sole object of "separating states" in order to break the "Hindu" or "Indian" hegemony in India. But, KVR as a dogmatic organization proved that it had no critical understanding of the Indian situation. 110 
It is ironical that KVR's compromise with "class enemies," thwarted the voices of the lower classes of Coorg. Instead of supporting the lower classes in Coorg (ideologically), KVR opined that the political stand of Dalits and backward communities, who were protesting against the separate state movement of Coorg, might protect the interests of "Karnataka's broker ruling classes" (Swathantra Karnataka, December 1997-February 1998). Hence, the dogmatic KVR was suggesting them to extend their full support to the "Kodava Nationalist movement." It underestimated the "intellectuality" and sensibility of the common masses to choose their own priorities. In spite of ideological cohesion of KVR and KRMM, the lower classes have not taken in the idea of "Kodava Nationalism."

They perceive it as dangerous as "Hindu Nationalism" of the right wing organizations. It should be noted that the so-called Kodava National Movement supported by both the ideologues of BJP-RSS, and KVR-KRMM was very much fond of a theory of "homogenization." This variety of homoginisation which was supported by both the extreme right and the extreme left is a peculiar one. Ironically, KVR's willful amnesia, that the right to "self determination" involves the will of the people to accept or associate or refuse the "nationalisms" of any variety.

KVR was never concerned about its own agenda of 1991, which talked big about the ideals like distribution of land to the landless labourers and Dalits. KRMM had ample opportunities of supporting the cause of some Dalits in Chikkaaluvaranahalli of Somwarpet taluk in 1997. Those landless Dalits who were backed by the activists of Revolutionary Youth Forum (RYF) ${ }^{21}$, pleaded with the government for the distribution of 250 acres of government land. KRMM supported M.C.Nanaiah, the then District Minister, who had rejected the request of the landless Dalits despite supporting them (Shakthi, 03.08.1997). KRMM had another opportunity to prove its credibility when the Kodaguspeaking backward castes including Dalits were marginalized by the caste elements of the "broker ruling class" (we can see such jargons in the official papers of KRMM) of Karnataka during the nomination of members for the Kodava Sahithya Academy, or when Kembatties were fighting for the reservation, or when 
Kembatties and Kudiyas were being humiliated in the so-called cultural programmes of the Academy. KRMM never intervened when a retired IFS officer Chonira Muthamma declared in 1996, that all the positions of the future separate state should be reserved for Kodavas alone (Thambanda 1998).

Interestingly, all the elected members from Coorg including the ministers and former ministers irrespective of the factor that whether they belonged to Kodava or Gauda castes, did not subscribe to the allegations of Nachappa. In an open rally of Kodagu Praja Vedike in 1998, B.A.Jeevijaya and D.A.Chinnappa, the former Ministers of Karnataka as well as the elected representatives of Coorg made it clear that organizations like KRMM made obstructions when Government wanted to introduce reforms in education, revenue, power generation and so on. Hence, they clarified that it was because of these separatist organizations, government could not materialize some of the important developmental works in Coorg. Surprisingly, in the end of 1990s, Nachappa argued,

Coorg's districts [sic] historical, cultural, racial, ethnic, linuistic and social fabric has been destroyed by successive governments; separate state of Coorg would be economically more viable; political representation alone can bring prosperity to the region which can happen only if Coorg gets statehood (Somaiah, 2001:83).

He also pointed out that he and his supporters want,

a political and not economic package for the development of the district, accompanied by a constitutional guarantee for their land, language and race as they are facing an identity crisis (Somaiah, 2001:83) (emphasis added).

Consequently, CNC has failed to regain the support of its allies and sympathizers after 2000. Surprisingly, in February 2003, Vaasu, a leader of KVR made it clear in an interview that his organization was not supporting CNC or its agenda. It is also interesting to note that most of the heads of Kodava Samaja (caste organization) along with the Former district minister M.C.Nanaiah severely criticized the casteist politics of CNC in April 2003 (Kodagu Samachara, April 2003). Akhila Kodava Samaja and Kodagu Ekikarana Ranga had already 112 
departed from the politics of CNC as stated earlier. It is an irony that $\mathrm{CNC}$ is adamantly and ridiculously attempting to focus its identity on the lines of caste and "racist" factors despite the wide oppositions from Kodava caste associations, on which CNC depended for its political future and fortunes. Perhaps, the Kodava Samaja groups thought that it would be too much to demand greater constitutional privileges for the Kodavas when two persons (M.M.Nanaiah from the Madikeri Constituency and Appachu Ranjan from the Somwarpet Constituency) from the Kodava caste got elected to the Legislative Assembly out of the three seats in Coorg (it should be noted that the other seat is reserved for Scheduled Tribes), two members (M. C. Nanaiah and Arun Machaiah) of Kodava caste were chosen to the Legislative Council and one person (Prema Cariappa) was nominated to the Rajya Sabha. It is remarkable that the Kodavas have been "elected" to all the available seats (except a seat reserved for the STs in Virajpet taluk) in an Indian democratic setup even though the population of Kodavas does not exceed fifteen percent of total population of Coorg. ${ }^{22}$ It is true in the case of other regions of India where the dominant castes always played hegemonic role in the parliamentary democracy.

The relationship of the BJP forces in the "ethnic movement" could be regarded as an unusual phenomenon by many scholars, who believe that, "Hindu chauvinism is far more dangerous than the chauvinism of ethnic minorities" (Basu and Kohli 1988:245). A greater potential danger for the backward castes and Dalits is the combination of Hindu chauvinism and chauvinism of the ethnic minorities, and more specifically, the role of liberal political parties in the "ethnic movement" led by the upper caste elements in Coorg. It is reasonable to support the demand for greater regional autonomy, which is the major essence of democracy. However, "a distinction should apparently be made between regional claims or movements backed by the oppressed classes and those backed by oppressor classes" (Vanaik 1990:115).

From the above account, we could make out that the upward mobile OBCs and Dalits especially OBCs are asserting themselves against the Upper caste highhandedness, throughout Karnataka. It is evident both in the case of Hyderabad Karnataka as well as 
Coorg region. They made it very clear that the non-representation of the majority of the population, i.e. people belonging to $\mathrm{OBC}$ and Dalit communities, is the major cause for the non-development of these regions. The apprehension of $\mathrm{OBC}$ and Dalits could be seen against the leadership of Lingayats, one of the dominant communities of Karnataka, in the separate state movement in NK and HK regions. We also see how the organized protest of the OBC and Dalit communities thwarted the leadership of the upper caste in the separate state movement in Coorg. It was quite evident in the Assembly Elections held in 2004. The appeal of CNC to boycott the elections has failed and, consequently, the Kodava candidates lost in the election; even though the supporters of $\mathrm{CNC}$ made attempts to project the Kodava candidates, the sympathizers of $\mathrm{CNC}$, irrespective of their political affiliation in the Assembly election. This kind of development is unusual in the Northern part of Karnataka since the movement for a separate state is very weak. More than that, the so-called movements for the separate state for NK and HK regions are mainly based on "economic issues" rather than the issues related to the "ethnicity" or "race" as being projected by the separatists in Coorg.

\section{References}

Achin, V. (1990). The painful transition bourgeois democracy in India. London: Verso.

Banjagere , J. (1996, February 16-19). (1996, September). Liberation of Karnataka and the new democratic revolution of India" in symphony of freedom-papers on nationality question-. The international seminar, New Delhi and All India Peoples Resistance Forum, Hyderabad.

Ganapathy, K. B. (1982). Kodagina jamma:karnataka sarakarakke ondu echarike. Kodagu: Kodagu original Inhabitant's Rights Protection Committee.

Janakki, N. (1996). Memoirs of underdevelopment-language and its identities in contemporary Karnataka. Economic and Political Weekly, October 12-19.

KVR. (1997). Yecharike kuchalakkikeri. Janavimukthi

Kumar, B. B. (1998). Small state syndrome in India. New Delhi: Concept Publishing Company.

Lankesh Patrike. (1997, December 24)., 
Muzaffar, A. (1997). Separatist movement in coorg. Economic and Political Weekly, (December 6-12),

Paul, B. (1990). The politics of India since independence, Cambridge: Cambridge University Press.

Peter, Schalk. (1997). Historisation of the martial ideology of the liberation tigers of tamil elam (LTTE)". South Asia, xx (2).

Ponnappa, K. C. (1997). A study of the origin of Coorgs. Madikeri :

KVR. (1994). Pranalike hagu Samvidhana (Constitution of KVR in Kannada). Karnataka Vimochana Ranga, State Committee, Bangalore.

Prison House: Rose Garden. (1993). Karnataka Vimochana Ranga. Bangalore.

Richter, G., Gazetter of Coorg, 1870 (1984). B RPublishing Corporation: Delhi.

Richter G. (1984). Ethnographical Compendium of Coorg 1887 .Coorg record office.

Rob Cole. (1870). Manual of Coorg. Coorg record office.

Robert C, O. (1996). Youth militancy and the rise of Srilanka: Tamil nationalism. M. Subratha K \& R Alison Lewis (Eds.), Subnational Movements in South Asia: Westview Press.

Saki. (1998). Karnatakas People and Their Past, Vimukthi Prakashana, Bangalore

Shakthi Coorg daily. (1997, November 30).

Somaiah , P. E. (2001). Movement for statehood in kodagu district of karnataka. Karnataka Journal of Politics, (1),

Srinivas M.N., The Religion and Society among the Coorgs of South India, Media Promoters \& Publishers Private Limited:Bombay, 1989 (1952).

Heera Associates Offset Printers, Madakeri. The kodagu (coorg) government in waiting its agenda, a budgetary profile of proposed kodagu state.

Vijay Poonacha, T. Prathyeka kodagu rajya: Mulanivasigalu mathu valasegararu. Prasaranga, Vidyaranya : Kannada University.

Vijay Poonacha, T. (2003). Language and identity politics in Coorg of South India. New Delhi.

Vijay Poonacha, T. (2000). Adhunika Kodagu. Prasaranga, Vidyaranya: Kannada University 
Vijay Poonacha, T. (2004). Conflicting Identities in Karnataka-Separate State and Anti-Separate State Movements in Coorg, Prasaranga, Vidyaranya: Kannada University.

${ }^{1}$ Critiques of Patil Puttappa say that whenever he is out of power, he starts criticizing the Government of Karnataka. They point out that, when he was a member of the Rajya Sabha and President of the "Kannada Kaavalu Samithi" (it had the status of a Minister of Karnataka), he did not question the "power-centres" of Karnataka and, instead, played an opportunist game in the politics of Karnataka.

2 Some of the KVR sympathizers organized processions in rural areas of the coastal region by canvassing the need of statehood for Tulu People in the early 1990s. This programme ended due to the lack of leadership and political commitment. In another attempt, Saadhu Shetty, who was associated with the Mumbai underworld, had taken initiation to launch a separate statehood for Tulu people in 1990s. According to the local people of Mangalore, it was an "eye wash" programme of Saadhu Shetty in order to escape threats from his enemies as well as the police. His organization lacked political awareness and motivation. The Tulu Separatist movement ended up with the death of Saadhu Shetty, who lost his life in an encounter with the police in Mumbai recently.

${ }^{4}$ In the seminar organized by the Kodagu Samachara group in April 2003, Mathanda Monnappa who is the President of Akhila Kodava Samaja as well as the leader of Kodagu Ekikarana Ranga made it clear that he or his organization did not have any connection with Karnataka Vimochana Ranga in spite of the series of letters he had received from KVR. He pointed out that he had kept aloof despite the consistent attempts of KVR to approach him.

${ }^{5}$ An official letter of Liwak, dated 10.06.1993

7 Copy of the Pamphlet circulated by LIWAK in 1993

8 A Pamphlet circulated by LIWAK in 1993

${ }^{9}$ Memorandum dated 11.11.1992, submitted by LIWAK to the President of India

${ }^{10}$ Memorandum dated 11.11.1992, submitted by LIWAK to the President of India

${ }^{11}$.Pranalike hagu Samvidhana (Constitution of KVR in Kannada), Karnataka Vimochana Ranga, State Committee, Bangalore, 1994.

12 The Rules of Akhila Kodava Samaja, printed at Hitavani Press, Virajpet, Kodagu. 
13 Vijay Poonacha Thambanda, Paper entitled "Language and Identity Politics in Coorg of South India" presented in the seminar organized by the Gandhi Hindusthani Sahithya Sabha, New Delhi and Department of Linguistics, Delhi University, (Theme of the Seminar: The role of Tribal Linguistic Group in the Implementation of Education Policy), 5-7, September 2003, New Delhi.

14 Pamphlets of Kodagu Rajya Mukthi Morcha, Printed at Smaran Enterprises, Madikeri, 1996, 1997.

15 The Kodagu (Coorg) Government in Waiting its Agenda, A Budgetary Profile of proposed Kodagu State, Heera Associates Offset Printers, Madikeri, p.1.

${ }^{16}$ A Memorandum dated 11.11.1992 submitted by LIWAK to the President of India

17 Shibu Soren became the Union Minister for Coal and Mines in the United Progressive Alliance government, after the Parliament Election of 2004. An arrest warrant was issued in the second week of July 2004 against him by a Jharkhand court in connection with the Chirrudih massacre in Bihar in 1975. The BJP-led Opposition members demanded to know the whereabouts of the Union Minister Shibu Soren, who they alleged was "absconding" after an arrest warrant was issued against him (The Hindu, 22.07.2004). Interestingly, there were rumours afloat in and around Madikeri about the presence in Kodagu of Shibu Soren, who had been evading arrest. The Kodagu police, who had heard the rumours, denied that Soren was present in the district. Soren was in Coorg in November 2002 to attend a rally organized by an organization [of Nachappa] (The Hindu, 23.07.2004). Reference

18 Letter dated 6, July 1998 from Vazhappady K.Ramamurthy, the Minister of Petroleum and Natural Gas, Union government of India, to the Prime Minister of India.

19 Pratyeka Kodagu Rajyakke Virodha, Kodagu Praja Vedike, 1997.

20 Pratyeka Kodagu Rajyakke Virodha, Kodagu Praja Vedike, 1997.

21 Revolutionary Youth Forum (RYF) is another CPI (ML) organization emanated in the early 1990s. I noticed that this organization of Dalits fighting for justice on the lines of Marxist-Leninist ideology in South India especially in Karnataka in 1990s.

22 It should be remembered that Nachappa has appealed all the Kodavas to boycott the Assembly and Loksabha elections of 2004 as a protest against the "injustice" done to the Kodavas. Ironically his own brother Nandhineravanda Viju (who is also an active member of CNC) with a 
BJP badge canvassed on behalf of BJP candidate Ranjan Appachu during the election day and actively participated in the election campaign. $\mathrm{CNC}^{\prime} \mathrm{s}$ active supporters like Mittu Chengappa (who is a member of Karnataka Pradesha Congress Committee) and Kuttanda Nanda Uthaiah (who is an active member of BJP) were also busy in campaigning for their candidiates (VijayaKarnataka, 27.04.2004). As explained in the previous chapter, KRMM/CNC's effort to boycott general elections of 1999 was a big failure in Coorg. He had lost his close associates like Mathanda Monnappa and others during 1999 elections. Interestingly in 2004 Assambly elections, both M.M.Nanaiah, the former district Minister of the Congress government and Ranjan Appachu, a BJP MLA lost their seats. M. M. Nanaiah lost his seat to a BJP candidate called K.G.Bopaiah a KodaguGauda by caste. Ranjan Appachu (BJP) has lost his seat to B.A.Jeevijaya (Indian National Congress-I), a former minister a Vokkaliga Gauda by caste. The term of M.C.Nanaiah as a member of Legislative Council was over by May 2004. 